\title{
FARKLI İNDEKSLER KULLANILARAK OTOMATİK KIYI ÇIZGGİSi ÇIKARIMI
}

\author{
Eyüp Kutluhan KULA ${ }^{1}$, Nusret DEMIR ${ }^{2}$ \\ ${ }^{1}$ Akdeniz Üniversitesi Uzay Bilimleri ve Teknolojileri bölümü lisans, Antalya,kutluhankula@hotmail.com \\ ${ }^{2}$ Dr. Öğr. Üyesi, Akdeniz Üniversitesi Uzay Bilimleri ve Teknolojileri bölümü, Antalya,nusretdemir@akdeniz.edu.tr
}

\section{ÖZET}

Kıyı çizgisinin otomatik olarak tespit edilmesi kıyılar boyunca fiziksel, kimyasal, biyolojik ve sosyal süreçlerin verimli bir şekilde izlenmesi için önemlidir. Test alanı uluslararası projelerin yoğun olarak faydalandığı Moore adasıdır. Bu çalışmada farklı indeksler için test edilmiş ve daha sonra Python dilinde arayüz hâline getirilerek tüm işlemlerin otomatik olarak parametre girmeden kısa bir sürede kıyı çizgisi çıkarımı yapılması amaçlanmıştır. Kullanılan görüntü Sentinel $2 A$ MS uydusuna aittir. Yöntemler ise; NDWI (Normalleştirilmiş Fark Su Indeksi), MNDWI (Modifiye Normalleştirilmiş Fark Su İndeksi), NDVI (Normalleştirilmiş Fark Bitki Örtüsü indeksi), MSAVI (Düzenlenmiş Toprak Etkisi Azaltılmış Bitki Örtüsü indeksi) indekslerinden oluşmaktadır. Indeks eşik değerleri, histogramlardaki kodlar kullanılarak elde edilip araştırmanın sonuçlarına göre MNDWI indeksi, Moorea Adası'nın kıyı şeridini ve kara-deniz modelini ortaya çıkarmak için büyük bir başarı ile kullanılabilir sonucuna varılmıştır.

Anahtar Sözcükler: kıyı çizgisi, histogram, Sentinel 2, otomasyon

\section{ABSTRACT}

\section{AUTOMATED COASTLINE EXTRACTION WITH USE OF DIFFERENT INDICES}

\begin{abstract}
Automated detection of the shoreline is important for efficient monitoring of physical, chemical, biological and social processes along the shorelines. The test area is Moore's island, where international projects are heavily utilized. In this study, it was tested different indices to detect the shorelines. An interface in Python language is also developped so that all the operations are performed automatically without any parameters. The image used is Sentinel $2 A$ MS images and the indices are; NDWI (Normalized Difference Water Index), MNDWI (Modified Normalized Difference Water Index), NDVI (Normalized Difference Plant Density Index), MSAVI (Regulated Soil Effect Reduced Vegetation Index) indices. The index thresholds were obtained using the histograms . the MNDWI index was the most efficient on efor the detection of shoreline in our study.
\end{abstract}

Keywords: coastline, histogram, Sentinel 2, automation, avatar

\section{GİRIŞ}

Kıyılar sürekli değişim hâlindedirler ve tespit edilmeleri daha iyi bir kıyı yönetimi için önemlidir. Bunun için uzaktan algılama etkin çözümler sunar (Demir vd. 2017). Bu çalışmada çok partnerli Idea Avatar projesinin (Web1) de test alanı olan, Moorea adasının kıyı çizgisinin herhangi bir parametre kullanılmadan, geliştirilen bir arayüz yardımı ile tespit edilmesi ele alınmıştır. NDWI (Normalize Fark Su İndeksi), MNDWI (Modifiye Normalize Fark Su İndeksi), NDVI (Normalize Fark Bitki Örtüsü indeksi), MSAVI (Düzenlenmiş Toprak Etkisi Azaltılmış Bitki Örtüsü indeksi) kullanımı ile histogram analizi ile eşik değerleri ile kıyı çizgileri belirlenip görüntü üzerinde elle sayısallaştırma ile üretilen kıyı çizgisi ile karşılaştırılarak kalitesi ölçülmüştür.

IDEA projesi, UC Berkeley, CNRS-EPHE, ETH Zürich, Oxford Üniversitesi, Hacettepe Üniversitesi, UC Santa Barbara ve MCR' deki araştırmacılar tarafından insan faaliyetlerinin ve küresel ısınmanın dünya üzerine etkisini fiziksel, kimyasal ve biyolojik özellikleri de barındıran 3D model üzerinde incelemek adına başlatılmıştır. Bu modele 3D Avatar ismi verilmektedir. Projede, insan-doğa etkileşiminin ve biyoçeşitliliğin en fazla olduğu tampon bir bölge seçilerek bölgenin avatarını oluşturmak hedeflenmiş̧ir. Bu kapsamda Moorea adası çalışmaya en uygun bölge olarak seçilmiştir. Araştırmacılar, insan da dahil tek hücreli canlılardan, çok hücreli karmaşık organizmalara kadar tüm biyolojik organizasyonların sosyo-ekolojik etkileşimle gelişim hızlarını, evrim aşamalarını ve bunun ileriye dönük modellenebilirliğini bu ada üzerinden inceleyip 3D Avatar üzerine aktaracaklardır. 


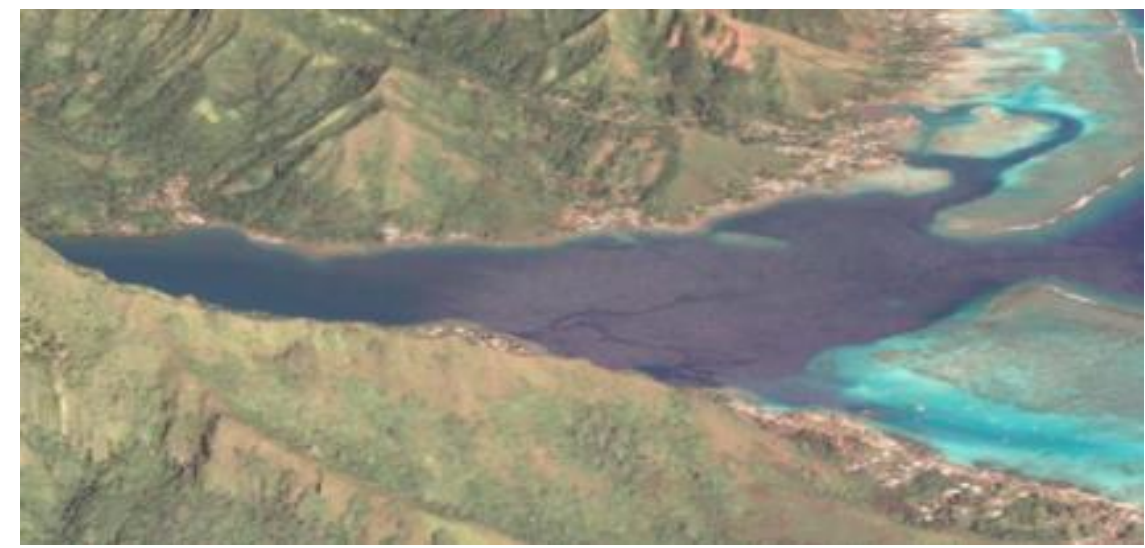

Şekil 1. Moorea Avatarı Önkesiti (Web 1).

\subsection{Test Alanı}

Pasifik Okyanusu'ndaki Fransız Polinezyası'nda bulunan Moorea adası, volkanik okyanus adası olup ebatları yaklaşık olarak San Francisco büyüklüğündedir. Moorea, deniz ve karasal çevreleri kapsayan doğal bir laboratuardır ancak oldukça büyük bir insan nüfusuna sahiptir (134 km²' de 17000 insan) ve karmaşık bir sosyo-ekosistemi açıklamaya yetecek tüm unsurları barındırmaktadır [Web 1].

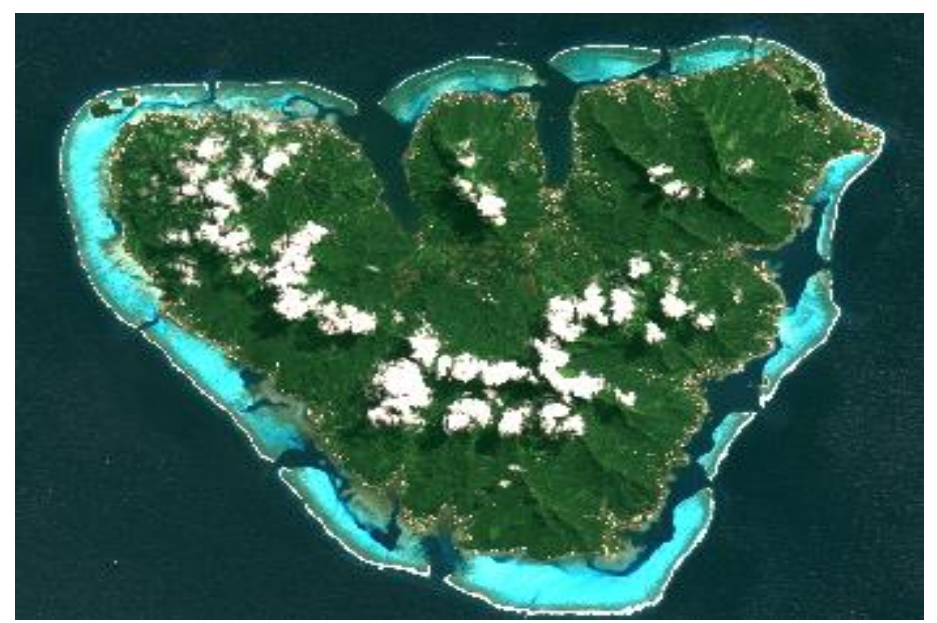

Şekil 2. Moorea Adas1.

\subsection{Kullanılan Veriler ve Araçlar}

Görüntü verisi olarak Sentinel 2A uydusunun multispektral bant verileri kullanılmıştır. Bu kapsamda kullanılan

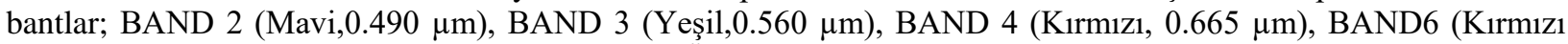
boyut bitki örtüsü,0.740 $\mu \mathrm{m}$ ), BAND 7 (Bitki Örtüsü Kırmızı Kenar, $0.783 \mu \mathrm{m}$ ), BAND 8 (NIR, $0.842 \mu \mathrm{m}$ ) bantlarından oluşmuştur.

Kullanılan araçlar ise;

- QGIS 2.14.9: Her türlü veri ve sonucu görselleştirmek için kullanılmıştır.

- Python 3.5.1: İndeks olutşturma histogram analizi, eşik değer belirleme ve su-kara yüzeylerini belirlemede kullanılmıştır.

\section{YÖNTEM}


Otomasyon, görüntülere indekslerin uygulanması, indeks sonuçlarından histogramların eşiklenmesi, ikili (binary) sonuçların elde edilmesi, daha sonraki aşamada vektöre çevirilip alan ve kıyı şeridi sonuçlarının elde edilmesi işlemlerini kapsamaktadır.

\subsection{Görüntü indeksleri}

İndeks metotları, Sentinel 2A MS uydu görüntülerinin ilgili bantlarıyla, Python dilinde oluşturulmuş arayüz sayesinde otomatik olarak hesaplanmıştır.

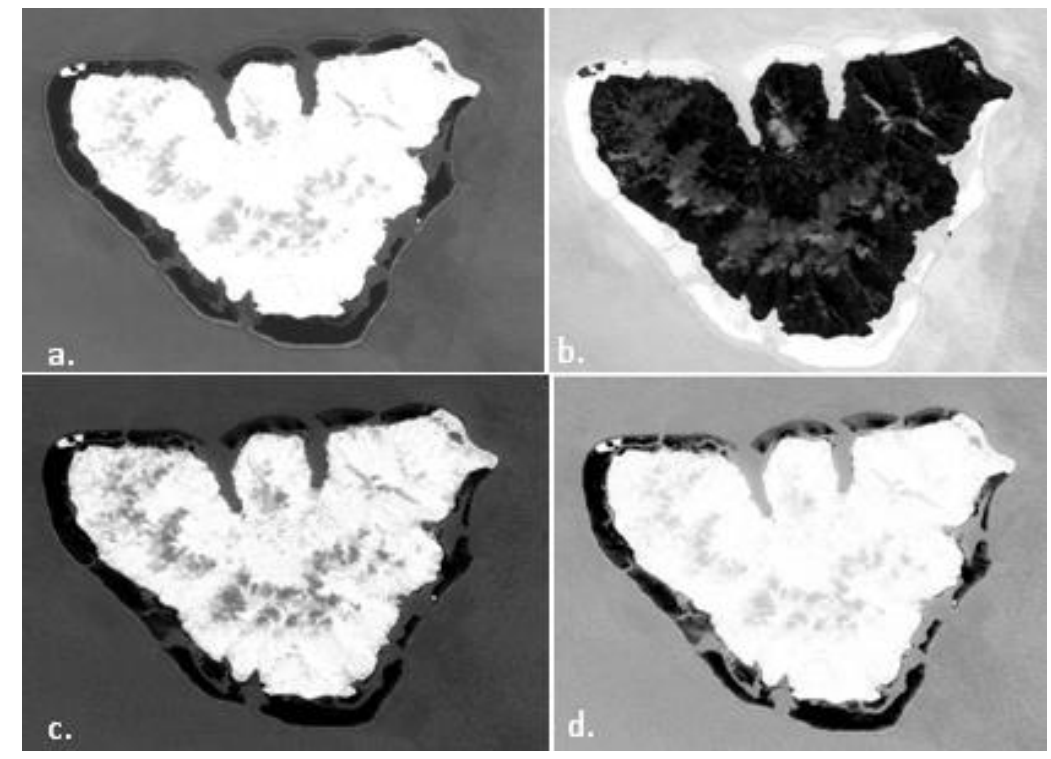

Şekil 3. a. NDWI uygulanmış görüntü (sol üst), b. MNDWI uygulanmış görüntü (sağ üst) c. NDVI uygulanmış görüntü (sol alt) alt d. MSAVI uygulanmış görüntü (sağ) .

İndeks formülleri aşağıda gösterilmiştir;

$$
\begin{aligned}
& M N D W I=\frac{\text { GREEN-SWIR }}{\text { GREEN }+ \text { SWIR }} \\
& N D V I=\frac{\text { NIR-RED }}{\text { NIR+RED }} \\
& N D W I=\frac{\mathrm{NIR}-\mathrm{SWIR}}{\mathrm{NIR}+\mathrm{SWIR}} \\
& M S A V I=\frac{2 * \mathrm{NIR} 2+1-\sqrt{(2 * \mathrm{NIR} 2+1)^{2}-8 *(\mathrm{NIR} 2-\mathrm{RED})}}{2}
\end{aligned}
$$

İndeks sonucu görüntüleri, Python kod dizininde bulunan eşik değerleri kullanılarak python programında eşiklendi. $\mathrm{Bu}$ işlem Python kod dilinde yazılmış aynı arayüz sayesinde otomatik olarak eşik belirlenerek ve uygulanarak yapılmıştır. Eşikler histogramların maksimum değerlerinden belirlenmiştir ve eşik değerlerinin üstünde kalan pikseller su olarak değerlendirilerek 1 değeri, , diğer nesneler için ise 0 değeri atanmıştır. 


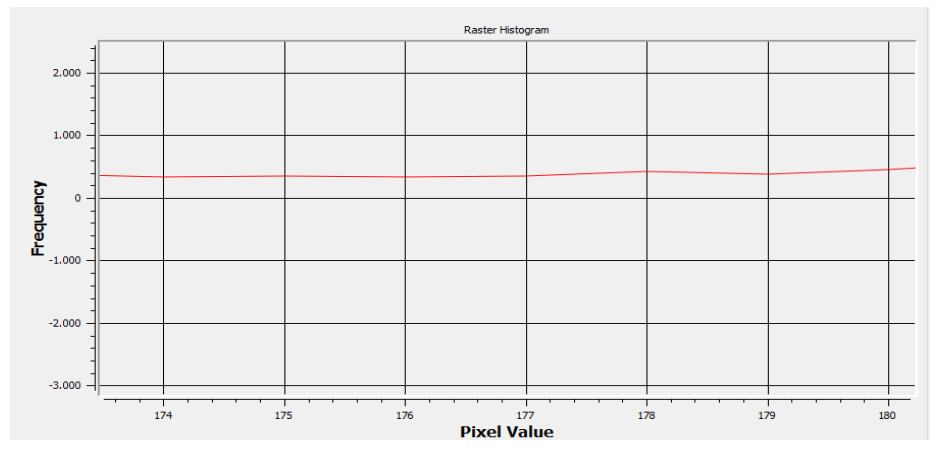

Şekil 4. Histogram maksimum değeri.

Çizelge 1.İndeks eşik değerleri tablosu.

\begin{tabular}{|c|c|}
\hline INDEKS & EŞİK DEĞERİ \\
\hline MNDWI & $>=178$ \\
\hline NDVI & $=<127$ \\
\hline NDWI & $>=127$ \\
\hline MSAVI & $=<229$ \\
\hline
\end{tabular}

Eşik sonuçları aşağıda gösterilmiştir;
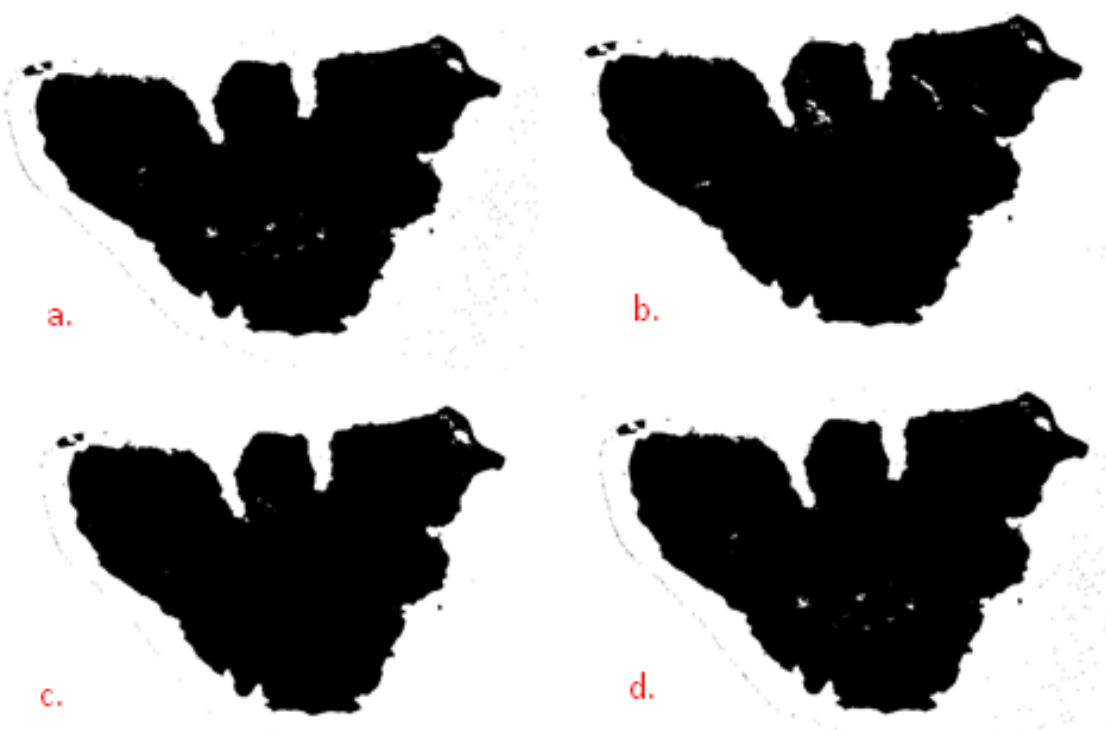

Şekil 5. a.Eşiklenmiş MSAVI görüntüsü (sol üst),b. Eşiklenmiş MNDWI görüntüsü (sağ üst) c. Eşiklenmiş NDWI görüntüsü (sol alt) d. Eşiklenmiş NDVI görüntüsü (sağ alt).

\subsection{Sonuçların Vektöre Çevirilmesi ve Doğruluk Analizi}

Sonuç görüntü vektör biçimine dönüştürülmüştür. Her bir indeks için sonuçlar Şekil 7’de görülmektedir. 


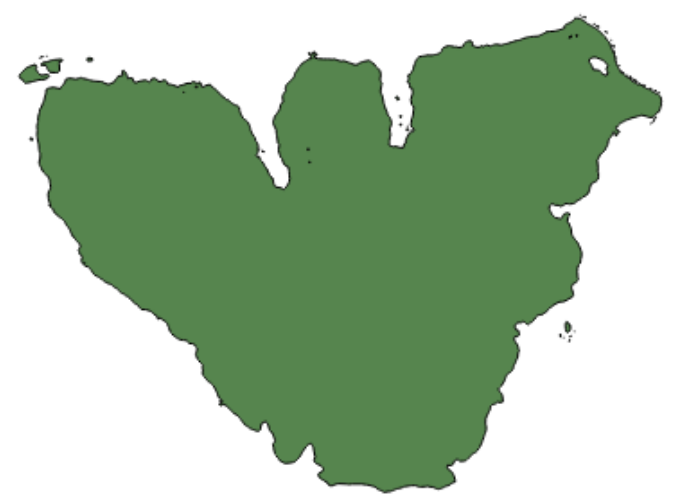

Şekil 6. Arayüz "SHP SONUC GÖRÜNTÜSÜ” buton çıktısı.

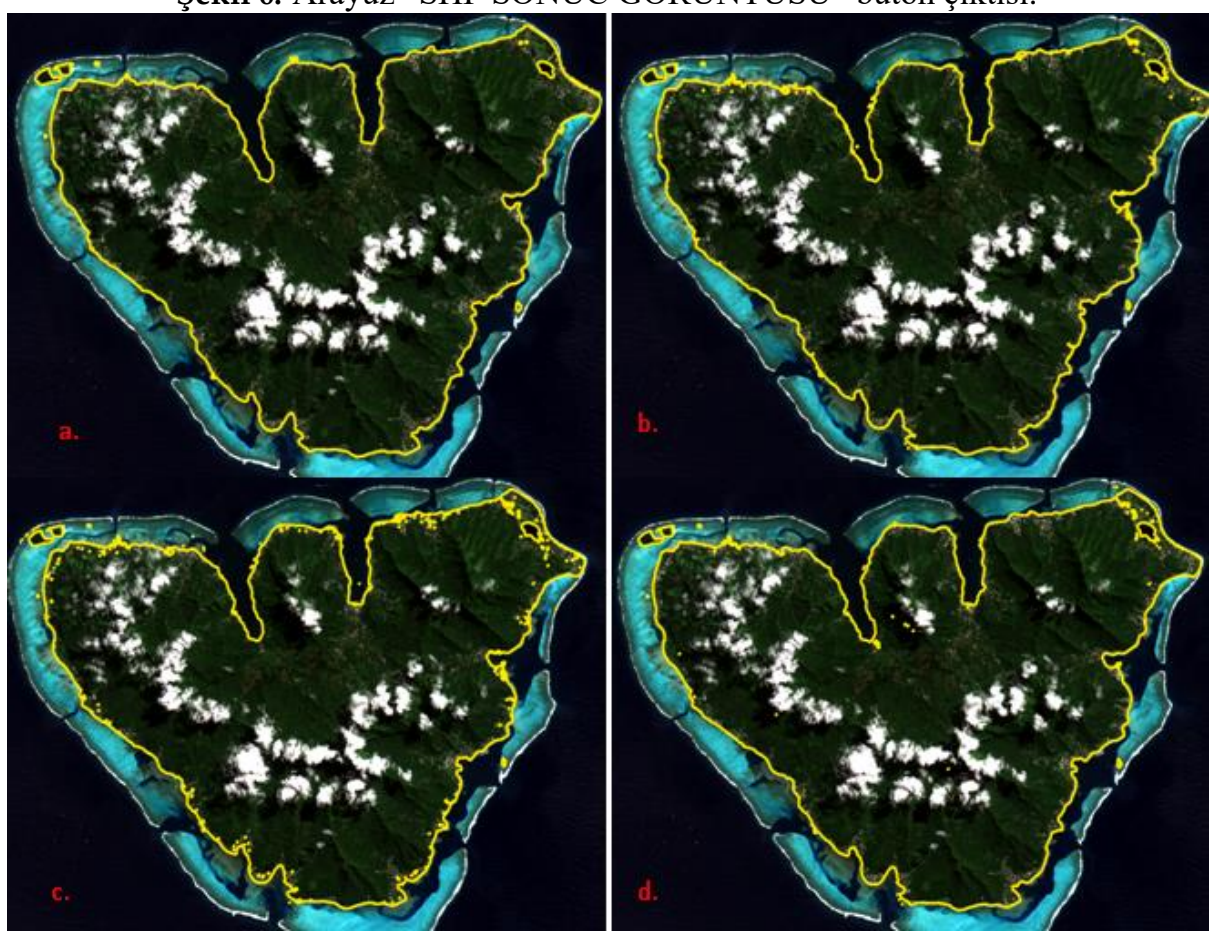

Şekil 7. a.MNDWI kıyı şeridi sonucu (sol üst),b. MSAVI kıyı şeridi sonucu (sağ üst) c. NDVI kıyı şeridi sonucu (sol alt) d. NDWI kıyı şeridi sonucu (sağ alt).

Sonuçların doğruluğunu belirlemek için yakınlık analizi QGİS yazılımında yapılmıştır. Buna göre vektör formatına çevirilen her sonuç görüntüsünde kıyı şeritlerine 10'ar metre aralıklarla nokta atılmıştır. Bu noktaların referans görüntüsündeki noktalarla mesafeleri ve istatistik bilgileri hesaplanmıştır. İşlem dizinlerini arayüz altında çalıştırmak amacıyla tüm kod blokları Python programının Tkinter modülünde birleştirilmiştir. Bu sayede oluşan arayüz sayesinde; indeks sonuç görüntüleri, vektörleri ve alan hesapları parametresiz bir şekilde otomatik olarak yapılıp elde edilmektedir. Bu işlem için uydu görüntüsünü indirmek ve gerekli bantları arayüzde seçmek yeterlidir. 


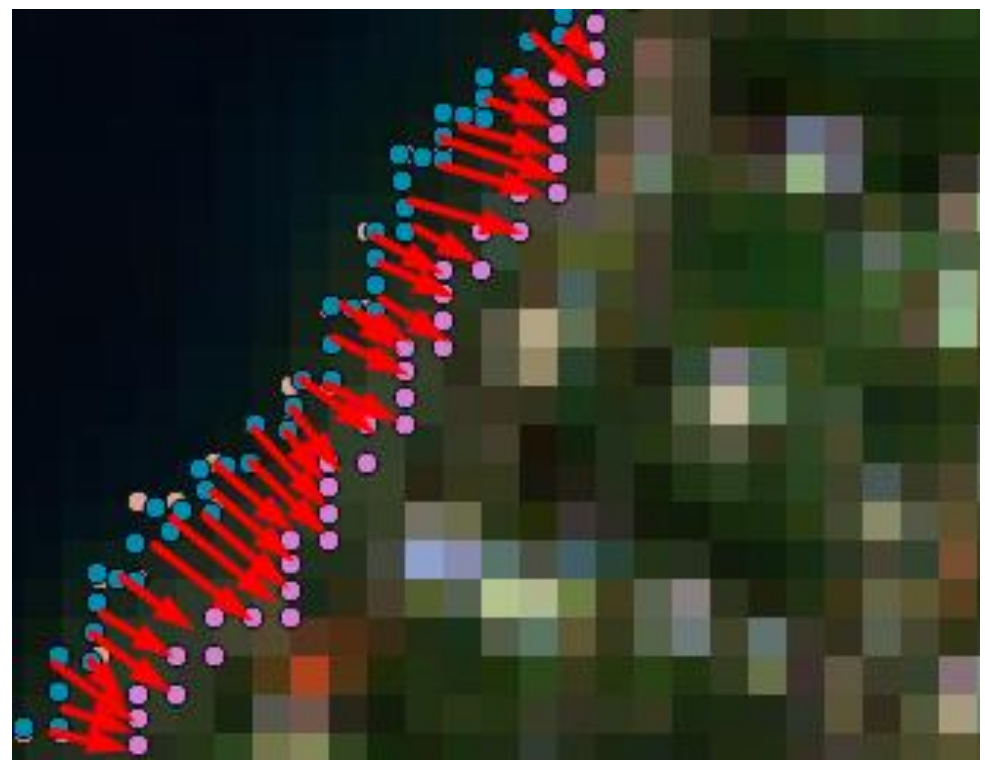

Şekil 7. Yakınlık analizi(Euclidian mesafesi).

Python dilinde yazılmış arayüz aşağıda gösterilmiştir (Şekil 8).

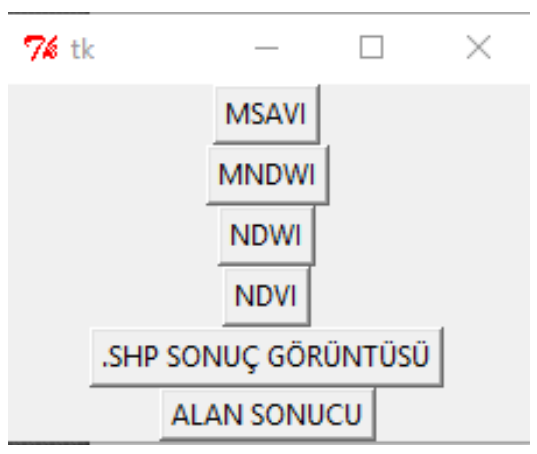

Şekil 8. Otomasyon arayüzü.

Arayüz kullanımı aşağıdaki işlem dizisi ile mümkündür:

1. Önce indeks yöntemleri uygulanmalıdır.

2. İndeks sonucundan sonra görüntüde odaklanılan alan kırpılarak clip.tif olarak kaydedilmelidir. Bunun sebebi bu işlem atlanıldığında arayüzün tüm görüntünün kara alanını hesaplayacak olmasıdır.(NOT: Tüm .jp2 alanını inceler.)

3. Bu işlemden sonra ikincil olarak. "shp sonuç görüntüsü butonu” seçilmelidir.

4. Tüm adımların sonunda son olarak "alan sonucu” butonu seçilmelidir."

\subsection{Doğruluk analizleri:}

Referans veri olarak kıyı şeridi el ile Sentinel görüntüsü üzerinden elde edilmiştir. Toplam kıyı şeridi, ada alanı ve referans veri ile karşılaştırılarak bulunan doğruluk değeri Çizelge 2'de görülmektedir. Çizelge 3'de yakınlık analizi ile elde edilen analiz sonu görülmektedir. 
Çizelge 2.Kıyı şeridi analizinin hassasiyet tablosu.

\begin{tabular}{cccc}
\hline Yöntem & Kıyı şeridi(km) & Ada Alanı $\left(\mathbf{k m}^{2}\right)$ & Doğruluk(Alansal, \%) \\
\hline NDWI & 74,84 & 133,4249 & 99,442 \\
MSAVI & 74,74 & 133,2549 & 99,315 \\
NDVI & 74,95 & 133,6185 & 99,586 \\
MNDWI & 75,12 & 133,9279 & 99,816 \\
REFERANS (RGB) & 75,26 & 134,1742 & REFERANS \\
\hline
\end{tabular}

Sonuç tablosu

Çizelge 3.Yakınlık analizi sonucu elde edilen doğruluk ölçütleri.

\begin{tabular}{|l|l|l|l|l|}
\hline & $\begin{array}{l}\text { ST SAPMA } \\
(\mathrm{m})\end{array}$ & ORTALAMA $(\mathrm{m})$ & $\begin{array}{l}\text { ORTALAMA } \\
(\text { Pixel })\end{array}$ & MEDYAN \\
\hline NDWI & 17,17187 & 11,56174 & 1,1562 & 6,20906 \\
\hline MSAVI & 17,71125 & 11,80364 & 1,1804 & 6,39157 \\
\hline NDVI & 18,77275 & 13,04023 & 1,3040 & 6,84262 \\
\hline MNDWI & 13,77462 & 13,55568 & 1,3556 & 14,11562 \\
\hline
\end{tabular}

Sonuç tablosu

\section{SONUÇ}

Proje kapsamında Sentinel 2A MS uydusundan Moorea adasına ait güncel olarak indirilen uydu görüntüleri yardımıyla MNDWI, MSAVI, NDWI, NDVI indekslerini otomatik olarak gerçekleştiren ve sonuç histogramlarından otomatik eşik değeri belirleyen bir arayüz yapılmıştır. Arayüz, eşik değeri yardımıyla sonuç ürünü olarak adanın yüzölçümünü vermektedir. Yani kıyı şeridini otomatik tespit edip canlılar için önemli olan bu sınır sayesinde kara ve denizi otomatik olarak ayırmıştır. Aynı işlem QGíS, SAGA GíS vb. uzaktan algılama temelli programlarda kullanıcıya ve arayüzlere bağlı olarak gerçekleştirilmek istendiğinde daha uzun sürelerde gerçekleştirilmektedir.

Geliştirilen bu arayüz sayesinde ise bu işlem parametresiz olarak sadece ilgili verinin seçilmesi ve gerekli fonksiyonların çalıştırılmasıyla 2 GB görüntü verisi 8 GB ram,4 GB ekran kartı ve 2.6 GHZ işlemci gücü olan bir bilgisayar ile yaklaşık $5 \mathrm{dk}$. da çözülebilmektedir. Bu süre işlemciden işlemciye değişiklik gösterip 2 dakikalara kadar kısalmaktadır. Projenin ilerleyen zamanlarında QGISS programıyla entegre bir modül oluşturup QGİS kaynak deposuna eklenti olarak eklenecektir. MDNWI indeksinin, incelenen tüm indeksler arasında en başarılı olduğu söylenebilir. MNDWI indeksi, Moorea Adası'nın kıyı şeridini ve kara-deniz modelini ortaya çıkarmak için büyük başarıyla kullanılabilir. İleride yapılacak çalışma olarak ise Landsat $8 \mathrm{MS}$ uydu görüntülerinin de aynı işlemlere tabii tutulup güncel olarak iki uydu sonuçlarının karşılaştırılması yapılacaktır.

\section{TEŞEKKÜR}

Bu çalışmada Moorea Avatar projesine katkı vermemizi sağlayan Hacettepe Üniversitesinden Doç.Dr. Sultan KOCAMAN'a teşekkür ederiz.

\section{KAYNAKLAR}

Demir N., Oy S., Erdem F., Bayram B., Şeker D.Z., 2017, INTEGRATED SHORELINE EXTRACTION APPROACH WITH USE OF RASAT MS AND SENTINEL-1A SAR IMAGES, ISPRS Ann. Photogramm. Remote Sens. Spatial Inf. Sci..IV-2(W4), pp.445-449.

Web 1: Moorea IDEA.2017. https://mooreaidea.ethz.ch/project[Erişim Tarihi: 21.11.2017] 
E.Kutluhan ve N.Demir: Farklı İndeksler Kullanılarak Otomatik Kıyı Çizgisi Çıkarımı 